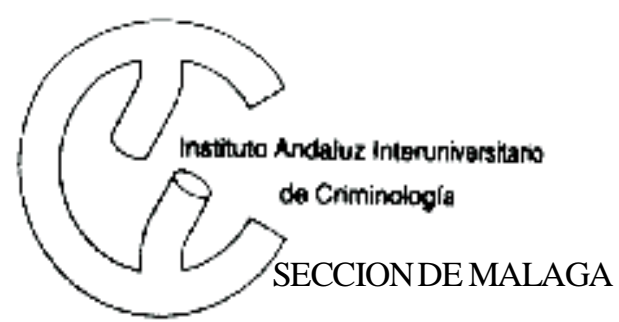

Director: Per Stangeland.

Coordinadora: $\mathrm{M}^{\mathrm{a}}$ Auxiliadora Durán Durán

Publicado por la Sección de Málaga del IAIC

Facultad de Derecho, Universidad de Málaga

Campus de Teatinos, 29071 MALAGA.

Los números de septiembre y octubre del Boletín Criminológico están dedicados a la prevención de la delincuencia. El IAIC, Sección de Málaga, organizó una mesa redonda de discusión sobre este tema en el mes de junio, contando con la participación de la policía, representantes del Plan Estratégico de Málaga y grupos de vecinos de la ciudad. En este boletín incluímos un extracto de la memoria presentada en dicho seminario. El profesor Marcus Felson de la Universidad de New Jersey, ( USA ), ofreció un esbozo de sus teorías sobre prevención de la delincuencia, habiendo sido incorporadas en estos dos números algunas de sus ideas.

\title{
PREVENCIÓN DE LA DELINCUENCIA EN LAS ZONAS RESIDENCIALES
}

La población de la ciudad de Málaga ha crecido rápidamente durante las últimas tres décadas. Enormes bloques de viviendas fueron construídos en gran cantidad $\mathrm{y}$ a precios asequibles, sin tener muy en cuenta ni la infraestructura de la ciudad ni el medio ambiente. Las zonas que rodean el casco antiguo de la capital - Perchel, Carranque, Ciudad Jardín, etc. están dominadas por bloques de 6 a 8 plantas, en los cuales entre 20 y 50 familias comparten el mismo portal. Los espacios comunes de estas vivivendas - el portal, los ascensores, zonas adyacentespresentan, en muchos casos, un pésimo estado de conservación. Una gran parte de estos bloques tienen 20 años o más de antigüedad $y$, con relativa frecuencia, muestran serios defectos en su construcción.

Estudios realizados en otros paises indican que estas construcciones son muy vulnerables a la de- lincuencia. Las encuestas anuales británicas a víctimas de la delincuencia ${ }^{1}$ utilizan una clasificación de viviendas en 11 tipos, estando los bloques de varias plantas y que albergan muchas familias en el grupo de mayor riesgo. En Estados Unidos y Suecia se ha procedido a la demolición de bloques de este tipo por ser considerados inhabitables. La "teoría de las ventanas rotas"2, ilustrada en la gráfica de la página siguiente, intenta explicar el ciclo negativo en el que puede verse inmerso este tipo de barrios:

- Signos iniciales de descuido y abandono en la calle (ventanas rotas, coches abandonados, basura, prostitución, venta de drogas) los hacen poco atractivos como zonas de paseo para sus habitantes, que se retiran a sus casas transitando lo más rápidamente posible desde el

\section{Autores: \\ Per Stangeland en \\ colaboración con \\ Marcus felson}

coche hasta las mismas.

- Las personas de clase media se sienten incómodas en el barrio, venden sus pisos y se trasladan a zonas más seguras y atractivas. Los precios de las viviendas bajan y aumenta el número de casas vacías u ocupadas de forma temporal. Los vecinos cada año se conocen menos.

- El deterioro social facilita la implantación y extensión de actividades delictivas. La compra-venta de drogas o servicios sexuales ofrece muchas oportunidades para la extorsión y los atracos callejeros. Las viviendas vacías resultan fácil presa del robo o

\section{Boletín Criminológico $N^{o} 13 \quad$ Septiembre 1995 Página 1}




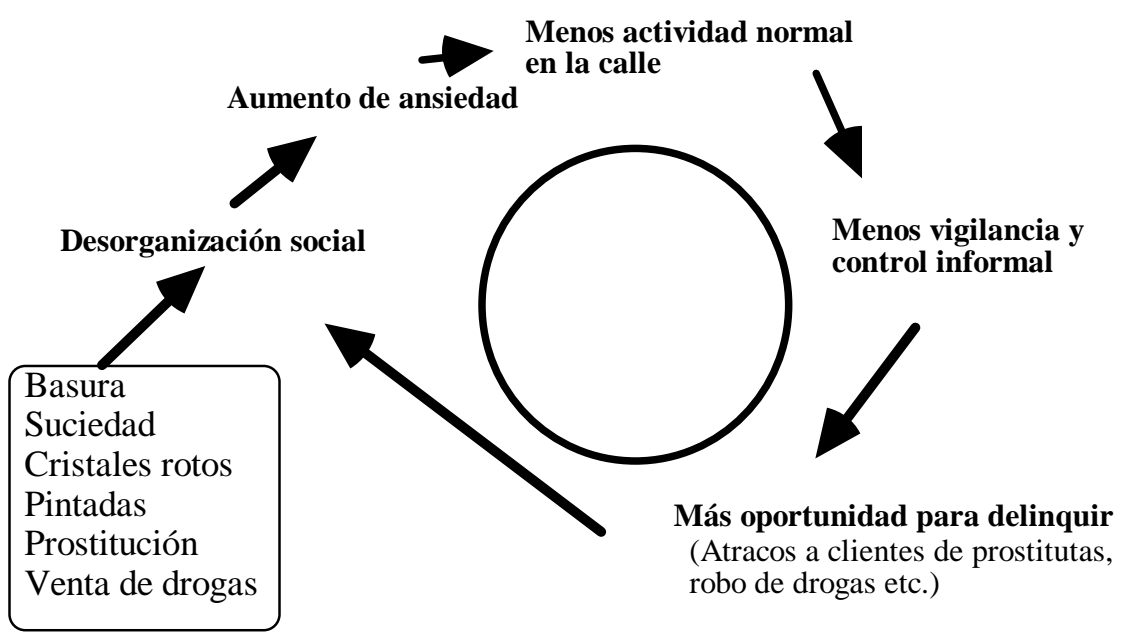

allanamiento. Los vecinos, que no se conocen, tampoco vigilan mutuamente sus casas.

\section{Capacidad de resistencia con- tra el deterioro social en ciu- dades españolas}

Sin duda, existen ejemplos de este círculo vicioso de deterioro en Málaga. Sin embargo, nuestras encuestas realizadas con objeto de establecer el riesgo de ser víctima de un delito en Málaga y su provincia, muestran que el círculo todavía no ha llegado a los extremos experimentados en otros países. Málaga es, aún, una ciudad básicamente segura. Tiene, por supuesto, cifras elevadas de tirones callejeros, daños y robos a vehículos. Sin embargo, se observan tasas moderadas de robos en casa, delitos violentos y agresiones sexuales. Así, en nuestra ciudad existen factores que ofrecen mayor resistencia al deterioro social de los barrios, los cuales no están presentes en las ciudades anglosajonas, Algunas de las razones que pueden ser aducidas para justificar dicho estado de cosas son las siguientes :

- La mayor parte de las viviendas son propiedad de sus residentes y los vecinos no se mudan de casa fácilmente. A pesar del crecimiento rápido que ha experimentado la ciudad, hay poca movilidad entre sus habitantes. Los vecinos, aunque se sientan incómodos en su barrio, no lo abandonan.

- La familia en España muestra una mayor estabilidad que en la cultura anglosajona o nórdica. Hay más habitantes en cada vivienda: la abuela vive en casa y los hijos mayores de edad también. La existencia de familias aporta más estabilidad al barrio y evita que la casa quede vacía durante el día, hecho bastante habitual en otros países.

- La animada vida nocturna contrasta con la existente en otros lugares. Los problemas de contaminación acústica producidos por bares y discotecas pueden ser considerables y un factor negativo para los vecinos. Sin embargo, el tránsito de personas que entran y salen de sus casas a todas horas ofrece, desde el punto de vista de la criminalística preventiva, una protección contra atracos y robos. La calle va- cía y sin establecimientos abiertos presenta un mayor riesgo.

Sin embargo, estos factores de protección no son inmutables y aunque, hasta ahora, han frenado el desarrollo de la delincuencia es previsible un aumento de la misma. Nuestras sugerencias de prevención están dirigidas a contrarrestar un desarrollo negativo e intercalar barreras ante el deterioro del control de los vecinos sobre su propio barrio.

\section{Teorías situacionales sobre la prevención}

Teorías tradicionales de prevención de la delincuencia realizaron propuestas a largo plazo, las cuales incluían mejoras en el sistema de educación, o programas para reducir la marginación y la pobreza.

Sin descartar la importancia de este tipo de programas, no debemos caer en el error de pensar que no se puede hacer nada contra la delincuencia en tanto existan desigualdades sociales 3 .

Aparte de personas dispuestas a delinquir, hacen falta dos elementos más para que un acto delictivo tenga lugar: un blanco apropiado y la ausencia de un vigilante. La delincuencia es, por tanto, la consecuencia de una confluencia en el tiempo y el espacio de estos tres elementos.

Es importante comprender que el delito depende no sólo del delincuente, sino también del blanco y de la ausencia de vigilante. Por ello, las teorías sobre el crimen que hablan exclusivamente del delincuente y de su moralidad o motivación no pueden explicar los actos ilegales.

En la sociedad moderna puede ocurrir que la delincuencia aumente aunque el número de delincuentes siga siendo idéntico: si resulta fácil robar, se roba más. Para explicar el aumento de la delincuencia hay que tener en cuenta

\section{Boletín Criminológico $N^{o} 13 \quad$ Septiembre 1995 Página 2}


los tres mentos y su confluencia en la vida cotidiana.

También es preciso comprender que el vigilante no suele ser un policía o un guardia de seguridad. Normalmente, la familia y los amigos resultan ser los vigilantes más efectivos.

Es posible que la palabra vigilante no resulte la más apropiada en este caso, puesto que la prevención del crimen se ejerce frecuentemente de forma no intencional y espontánea. Por ejemplo, cuando tres miembros de una familia van de compras juntos no tienen la idea de que así evitan ser víctima de un delito, pero de hecho están protegiéndose entre sí.

La vigilancia o control informal constituye una protección más eficaz contra el crimen que el con- trol formal, la vigilancia planeada.

\section{fáciles» \\ La eliminación de «blancos \\ Una buena parte de la delin-} cuencia surge como respuesta inmediata a una situación concreta: la presencia de un objeto atractivo que se encuentra sin vigilancia. La eliminación de «blancos fáciles» reduce la delincuencia. Se trata de identificar las situaciones inmediatas que crean tentaciones excesivas para la comisión de actos delictivos. Por ejemplo: se puede pensar que los actos de vandalismo contra teléfonos públicos son motivados por la escasa oferta de actividades constructivas y de ocio para adolescentes. Sin embargo, eso no explica que algunos teléfonos sean destrozados con mucha más frecuencia que otros. El rediseño de los teléfonos públicos en Gran Bretaña, Australia y EE.UU., ha hecho posible una reducción del vandalismo.

Este tipo de prevención situacional consiste en la realización de reformas urbanísticas a pequeña escala. El rediseño de zonas verdes y parques públicos, por ejemplo, puede reducir el peligro de atracos y tirones. Se trata de reducir el número de vías de escape para el ladrón: con una sola entrada y salida en el parque se producen menos robos. $\mathrm{El}$ atraco $\mathrm{o}$ agresión sexual en portales $\mathrm{y}$ espacios cercanos al ascensor, en bloques de viviendas, se puede reducir mejorando la visibilidad. Un portal oscuro y sin visibilidad di-

\section{SERENOS DE BARRIO}

- Establecimiento de un programa de formación para jóvenes sin empleo en el sector de servicios comunitarios. Se trata de impartir cursos sobre el mantenimiento técnico de edificios, asistencia social a los vecinos, así como vigilancia y prevención de la delincuencia. Los cursos podrían ser organizados por el INEM en colaboración con profesionales de mantenimiento técnico, servicios sociales y policía.

- Puesta en marcha de un proyecto piloto en uno o dos barrios de la ciudad, los cuales recibirán apoyo especial por parte del ayuntamiento y de la policía. Estos barrios han de presentar algunas características específicas, no siendo extremadamente conflictivos, pero estando en situación de riesgo en cuanto al incremento de la delincuencia.

- Los alumnos de este programa de formación serían contratados como "serenos de barrio" o "porteros de barrio" por el ayuntamiento o una fundación semi-pública. Se les ofrecería un contrato en prácticas de uno o dos años de duración, y, además del sueldo correspondiente, un plus por trabajo nocturno.

- La financiación del proyecto se realizará a través de fondos europeos destinados a la creación de empleo para jóvenes, o dentro del marco de programas europeos dirigidos a mejoras en la infraestructura urbana. En muchos casos, la C.E.E. aporta hasta el $75 \%$, mientras el resto tendría que ser financiado por el ayuntamiento y comunidades de propietarios

- Los "serenos de barrio" mantendrían una estrecha colaboración con la Policía Local y Nacional. En el distrito elegido para este programa se establecerá una coordinación entre ambos cuerpos, de modo que una brigada de policias estarían dedicados exclusivamente a establecer contactos con los ciudadanos dentro del distrito. Tendrían un local a su disposición -central de los serenos o porteros de barrio- donde los vecinos podrían presentar sus quejas o comentarios a los organizadores. Los "serenos de barrio" dispondrían de un teléfono movil o radio VHF para poder llamar a su central y a la de la policía.

\section{Boletín Criminológico $N^{o} 13$ Septiembre}




\section{POLICIAS DE BARRIO}

En varios países se intenta descentralizar las comisarías de policía, estableciendo sucursales más pequeñas que permitan un mejor conocimiento del barrio. La experiencia ha resultado positiva en relación a la aceptación social de la policía y a la atencion que la policía del barrio puede prestar a tareas preventivas. ${ }^{5}$ Sin embargo, es una reforma costosa y supone un peor aprovechamiento de recursos humanos y técnicos. $\mathrm{La}$ situación española es distinta al disponer de una Policía Local organizada por municipios, y una Policía Nacional, La orientación hacia la comunidad implicaría a ambos cuerpos. De forma experimental se podrían establecer colaboraciones puntuales, como las siguientes :

- Policía Local y Nacional, conjuntamente, destinarán una brigada a tareas informativas sobre prevención de la delincuencia. Esta brigada puede ayudar y asesorar a ciudadanos y comunidades de propietarios sobre medidas preventivas en general y, en especial, sobre zonas conflictivas en el barrio. Además mantendrá contactos con el ayuntamiento, avisando sobre deficiencias urbanísticas y sugiriendo medidas. Debe también ofrecer peritaje técnico en planes urbanísticos, con objeto de facilitar la prevención. Este asesoramiento podría concretarse en aspectos tales como construcción de viviendas sociales o remode-lación de parques y playas. La colaboración entre concejales de urbanismo y seguridad ciudadana resultaría fundamental. recta es más peligroso que otro iluminado y visible por parte de los vecinos o posibles traseúntes.

\section{Mejoras en los sistemas de vigilancia}

Aparte de la atención a detalles arquitectónicos, los programas modernos de prevención se concentran en recomendar mejoras en los sistemas de vigilancia. Un factor que ha contribuido al aumento de la delincuencia urbana en las últimas décadas es el desmantelamiento de sistemas de vigilancia tradicional. Muchos puestos de trabajo que supervisan actividades y protegen bienes han sido eliminados para reducir gastos, abriendo así puertas a la delincuencia. Ejemplos de este tipo de vigilancia son los serenos, porteros, jardineros y guardas en, por ejemplo, obras de construcción, parques y almacenes.

En nuestra ciudad, al igual que en la mayoría de las capitales españolas, las comunidades de propietarios de los edificios están suprimiendo a los porteros, los cuales cumplen funciones de suma importancia para la prevención de la delincuencia, al vigilar el edificio y mantener cierto control sobre quién sale y entra. Tradicionalmente, los porteros tenían su vivienda dentro del edificio donde trabajaban y efectuaban de este modo un control también fuera del horario de trabajo.

Sin embargo, gran parte de las comunidades de propietarios, para reducir gastos, han instalado un sistema de portero electrónico y contratado la limpieza de las escaleras y de las zonas comunes con una empresa de servicios.

El proyecto "Serenos de barrio" intenta crear empleo para jovenes en paro, formándoles en el mantenimiento de edificios, servicio social a vecinos, así como tareas de prevención y vigilancia.

Este propuesta está basada en un modelo holandés ${ }^{4}$, que obtuvo bastante éxito en la reducción de actos de gamberrismo, pintadas y pequeños delitos en las zonas donde se realizó. También se consiguió la aceptación del proyecto entre los ciudadanos. Una consecuencia de ello ha sido que muchos de los serenos fueron contratados por las comunidades de propietarios tras la finalización del proyecto. Otra opción laboral para los participantes en el programa holandés fue la contratación en el sector de seguridad privada o pública.

Así se mostró que iniciativas de prevención de delincuencia también pueden convertirse en iniciativas para crear empleo.

\section{Bibliografía}

Mayhew et. al.:'The 1988 British Crime Survey". Home Office Research Study No 111, 1989.

2 Wilson, J.Q. y Kelling, G.: "Broken windows". The Atlantic Monthly, Marzo 1982, p. 29-38. Skogan, Wesley G: "Disorder, crime and community decline". En Hopr, T. y Shaw, M. (ed.): "Communities and crime reduction". Home Office Research and Planning Unit, 1988 p. 48-61.

${ }^{3}$ Clemente Díaz, M. : "La prevención de la delincuencia : la importancia del diseño ambiental".. Estudios de Psicología, no , 17, 1984.

4 Hesseling, R.B.P. "Social caretakers and preventing crime on public housing estates". La Haya, 1992.

5 Rico, José y Salas, Luis: "Inseguridad ciudadana y policía”. Madrid 1988. Barberet, Rosemary:" La policía y la investigación criminológica”. En: Cuadernos de la Guardia Civil, 1993 № 9. Friedman, Robert: “Community policing” New York, 1992.

\section{Boletín Criminológico $N^{o} 13 \quad$ Septiembre $1995 \quad$ Página 4}

